\title{
CD133 + Stem Cell Therapy Effects on Myocardial Regeneration Through Increased Vascular Endothelial Growth Factor Correlate with Cardiac Magnetic Resonance Imaging Results in Coronary Artery Bypass Graft Surgery Patients with Low Ejection Fraction
}

\author{
Tri Wisesa Soetisna, MD, MHA, PhD \\ Department of Cardiothoracic and Vascular Surgery, National Cardiovascular Center Harapan Kita, Jakarta, Indonesia; Department \\ of Surgery, Faculty of Medicine, Universitas Indonesia
}

\section{ABSTRACT}

Background: Stem cell implantation has become a promising therapy for heart failure due to coronary heart disease (CHD). CD133+ stem cell therapy, together with increases of vascular endothelial growth factor (VEGF) and other growth hormones, can induce myocardial repair.

Objective: To prove that VEGF plays a role in cardiac regeneration.

Methods: Twenty-six patients with CHD and ejection fractions $<35 \%$ from Harapan Kita Heart and Vascular Center, Jakarta, Indonesia, from 2016 to 2018 were randomized into 2 groups. The treatment group underwent coronary artery bypass graft $(\mathrm{CABG})+\mathrm{CD} 133+$ implantation, and the control group underwent CABG only. Six months later, perfusion and myocardial function were assessed by ejection fraction, wall motion score index (WMSI), ventricular dimensions, and scar size using cardiovascular magnetic resonance imaging. VEGF was assessed with enzyme-linked immunosorbent assay.

Results: There was significant improvement in ejection fraction $(8.69 \% \pm 9.49 \%$ versus $1.43 \% \pm 7.87 \%, P=.04)$, WMSI $(0.51 \pm 0.48$ versus $-0.01 \pm 0.21, P=.003)$, and scar size $(25.46 \pm 12.91$ versus $27.32 \pm 12.92 \mathrm{~mm}, P=.047)$ and a significant increase in blood VEGF levels $(61.05 \pm 63.01$ versus $19.88 \pm 33.78 \mathrm{pg} / \mathrm{mL}, P=.01)$. Improvements in perfusion defects $(13.69 \pm 5.03$ versus $11.53 \pm 5.81 P=.32)$ and ventricular dimensions $(-27.59 \pm 84.48$ versus $-19.08 \pm 36.79$ $\mathrm{mm}, P=.06)$ were not statistically significant.

Conclusion: CD133+ stem cell implantation improves myocardial function. The increase in VEGF levels is expected to continue improving restoration of myocardial function when myocardial perfusion improvement is still not optimal.

Received March 3, 2021; received in revised form May 3, 2021; accepted May 5, 2021.

Correspondence: Tri Wisesa Soetisna, Department of Surgery, Faculty of Medicine, Universitas Indonesia, Letjen. S. Parman, kav. 87, Fakarta 11420, Indonesia (e-mail: tricts2000@yahoo.com).

\section{INTRODUCTION}

In recent years, coronary artery bypass graft (CABG) accompanied by CD133+ stem cell implantation has become a promising therapy for treating ischemic heart failure [Ahmadi 2007]. When myocardial infarction occurs, the existing resident stem cells are insufficient to repair myocardial and vascular cells because the endogenous regenerative capacity of the heart muscle and the resident stem cells cannot compensate for myocardial damage. Implanted stem cell therapy, with its paracrine and autocrine effects, contributes to heart muscle repair and regeneration [Haxhibeqiri-Karabdic 2014]. CD133+ is a subtype of multipotent bone marrow mononuclear cells that have strong angiogenesis capability, high transplantation success rate, and high homing ability and secrete vascular endothelial growth factor (VEGF) [Dawn 2009; Goldstein 1992; Haxhibeqiri-Karabdic 2014].

Lazar et al [2018] suggested that VEGF released in ischemic conditions begins with the process of releasing exosomes by ischemic cells [Shibuya 2011]. Exosomes are vehicles that carry genetic material (messenger RNA, microRNA, DNA, and small proteins) to induce the release of VEGF and other growth hormones, which enhances myocardial repair through angiogenesis, activation of hibernating myocardium, prevention of apoptosis, matrix formation, and cardiomyogenesis. This study aims to prove that VEGF plays a role in cardiac regeneration [Dimmeler 2005; Strauer 2002; Steinhoff 2017; Urbich 2004].

\section{METHODS}

\section{Patient Selection}

In this study, 26 patients were divided into 2 groups. The first group (treatment) of 13 patients underwent CABG with CD133+ implantation, and the second group (control) of 13 patients had CABG only. Table 1 shows the characteristics of the study subjects, with both groups representing similar characteristics of age, sex, kidney function, and other comorbidities, except for left ventricle ejection fraction (LVEF), which was lower in the control group. Most of the patients had both modifiable and irreversible risk factors. 


\section{Study Protocol}

This experimental study was conducted using a parallel, open-label, single-blinded design at National Cardiovascular Center Harapan Kita from March 2016 to June 2018. This study received approval from the Health Research Ethics Standing Committee of Harapan Kita National Cardiovascular Center and the Faculty of Medicine, University of Indonesia. This study is registered at ClinicalTrial.gov (NCT028709330). All patients gave written informed consent. The 26 patients selected, who met the criteria for selecting research subjects, had a low LVEF and underwent CABG surgery in the Adult Cardiac Surgery Division at National Cardiac Center Harapan Kita.

\section{Bone Marrow Aspiration}

Patient received local anesthetic, and 190 to $210 \mathrm{~mL}$ bone marrow was aspirated from the posterior iliac crest. The sample was diluted with $25 \mathrm{~mL}$ normal saline containing 40,000 U heparin. The aspirate was then transferred to a container.

\section{CD133+ Separation Process}

Phosphate-buffered saline was added to a total aspirate volume of $450 \mathrm{~mL}$ and centrifuged to remove platelets. A total of $1.5 \mathrm{~mL}$ Magnetic MicroBeads and anti-CD133 label (Miltenyi Biotec, Bergisch Gladbach, Germany) were added, and the mixture was incubated at room temperature for 30 minutes. CD133+ separation was performed using the
CliniMACS Magnetic Separation Tool (Miltenyi Biotec). The final product was stored at $4^{\circ}$ to $8^{\circ} \mathrm{C}$. The final aspiration volume for implantation is $20 \mathrm{~mL}$, with CD133+ counts ranging from 5 to 10 million cells. Cell count, evidence of sterility, purity, and viability of CD133+ were assessed in $10-\mathrm{mL}$ samples using flow cytomery (Aria III; BD Biosciences, Franklin Lakes, NJ). The purity of the final CD133+ product was $84.4 \%$ to $90.1 \%$, with a viability of $95.2 \%$ to $94.4 \%$.

\section{Surgery}

Anesthesia and on-pump CABG were performed according to usual surgical protocols. All 26 patients received cold blood cardioplegia with 3 to 4 grafts to achieve complete revascularization with the most common left internal mammary artery to left anterior descending artery (LADA), saphenous vein graft (SVG) to left circumflex artery, and of SVG to right circumflex artery or SVG to intermediate coronary artery [Ahmadi 2007; Dawn 2009; Haxhibeqiri-Karabdic 2014]. CD133+ cells were prepared in $201-\mathrm{mL}$ syringes with $25 \mathrm{G}(0.5 \times 25-\mathrm{mm})$ needles. CD 133 + transseptal and transepicardial implantation were performed by tracing the LADA, and correct needle placement in the interventricular septum was assessed by transesophageal echocardiographic guidance. Each $0.5-\mathrm{mL}$ injection of CD133+ was given at a distance of $\sim 1.0 \mathrm{~cm}$. Ten injections were distributed in the transseptum area, and 30 total injections were injected along the border area of the hypokinetic/perfusion segment identified by

Table 1. Subject Characteristics

\begin{tabular}{|c|c|c|c|}
\hline Age $(y)$ & $54.61 \pm 8.07$ & $57.46 \pm 6.33$ & .32 \\
\hline Systolic blood pressure $(\mathrm{mmHg})$ & $121.92 \pm 14.37$ & $126.53 \pm 19.60$ & .5 \\
\hline Diastolic blood pressure $(\mathrm{mmHg})$ & $78.00 \pm 12.03$ & $72.46 \pm 15.36$ & .2 \\
\hline Smoking & 11 & 9 & .65 \\
\hline Dyslipidemia & 6 & 11 & .09 \\
\hline Hypertension & 9 & 7 & .68 \\
\hline Family history of $\mathrm{CHD}$ & 7 & 8 & .69 \\
\hline Menopause & 1 & 1 & 1 \\
\hline NYHA grade III or IV & 4 & 4 & 1 \\
\hline CCS grade II or III & 1 & 2 & .53 \\
\hline LVEF (\%) & $25.88 \pm 5.66$ & $30.18 \pm 3.85$ & .04 \\
\hline Scar size (\% change from baseline) & $27.76 \pm 15.76$ & $24.45 \pm 13.73$ & .47 \\
\hline Wall motion score index & $2.32 \pm 0.17$ & $2.07 \pm 0.31$ & .08 \\
\hline
\end{tabular}

Data are mean \pm SD or $n$. NYHA indicates New York Heart Association. 
cardiac magnetic resonance imaging (MRI) or visible scarring and discoloration of the epicardial muscles [Ahmadi 2007; Dawn 2009; Haxhibeqiri-Karabdic 2014; Li 2016].

\section{Follow-Up}

Patients were assessed at the same imaging facility in our hospital before surgery and 6 months after the procedure. VEGF levels in the blood were measured in our laboratory using enzyme-linked immunosorbent assay (ELISA). Our imaging facilities are equipped with a Philips Achieva $1.5 \mathrm{~T}$ MRI. All subjects underwent rest and stress (adenosine 140 $\mu \mathrm{g} / \mathrm{kg} / \mathrm{min}$ ) MRI with a dimeglumine gadopentate contrast agent $(0.05 \mathrm{mmol} / \mathrm{kg})$. LVEF, scar size, and wall motion score index (WMSI) were analyzed using cvi42 software.

\section{Statistical Analysis}

All statistical data were analyzed using IBM SPSS Statistics, version 21.0 (SPSS, Chicago, IL). Continuous data are presented as means \pm standard deviation $(\mathrm{SD})$ or median and interquartile range; Categorical data are presented as numbers and percentages. The Shapiro-Wilk test was used to assess normality. We calculated the sample size by MannWhitney test with power of $80 \%$, resulting in minimum samples of 13 subjects. Data were analyzed by independent $\mathrm{t}$ test or Mann-Whitney test. Measurement of the scar size proportion is presented as improved and nonimproved categorical data compared by $\chi^{2}$ test. In all cases, a $P$ value $<.05$ was considered statistically significant.

\section{RESULTS}

\section{Selection Process and Patient Characteristics}

Twenty-six patients were recruited for this study and randomly assigned to 1 of 2 groups to be evaluated. Both groups demonstrated similar characteristics of sex, age, and comorbidities, except LVEF, which was lower in the treatment group than in the control group. The selection of subjects was randomized and in concurrence with the inclusion criteria. Hemodynamic parameters were similar between groups. The subjects in this study were all $>50$ years old, mostly male $(92.13 \%)$ and active smokers $(76.92 \%)$, and had hypertension and diabetes (61.54\%) (Table 1). In sum, most patients in this study had both modifiable and unmodifiable risk factors for coronary artery disease.

\section{Cardiac Function}

In this study, the primary end point to prove cardiac function improvement was VEGF measured by ELISA and LVEF, WMSI and scar size assessed by cardiac MRI. We found a significant difference in change in LVEF $(8.69 \% \pm 9.49 \%$ versus $1.43 \% \pm 7.87 \%, P=.04)$ (Figure 2$)$, WMSI $(0.51 \pm 0.48$ versus $-0.01 \pm 0.21, P=.003$ ) (Figure 3 ), and scar size regression $(25.46 \pm 12.91$ versus $27.32 \pm 12.92, P=.047)$ (Figure 4) and a significant increase in VEGF levels $(61.05 \pm 63.01$ versus $19.88 \pm 33.78, P=.01$ ) in the treatment group (Table 2). Categorical analysis using the $\chi^{2}$ test showed greater improvements in scar size proportion in the treatment group than the control group. However, improvement in perfusion defects $(13.69 \pm 5.03$ versus $11.53 \pm 5.81, P=.32)$ and ventricular dimensions (left ventricular end systolic volume, $126.91 \pm$ 86.03 versus $149.33 \pm 44.96 \mathrm{~mm}, P=.07$; left ventricular end diastolic volume, $-27.59 \pm 84.48$ versus $-19.08 \pm 36.79 \mathrm{~mm}, P$ $=.06)$ were not statistically significant. There was a significant increase in VEGF levels $(61.05 \pm 63.01$ versus $19.88 \pm 33.78$ $\mathrm{pg} / \mathrm{mL}, P=.01)$ in the treatment group compared with the control group.

\section{Adverse Events}

Four patients ( 2 from each group) were not evaluable at study end. In the treatment group, 1 patient died of sepsis, and 1 patient died from hemodynamic instability after fasciotomy for compartment syndrome. In the control group, 1 patient died of sepsis, and 1 patient decided to withdraw from the study.

\section{Discussion}

Neovascularization is an ischemic cell defense mechanism to survive within the ischemic period, proven by the formation of new blood vessels that supply nutrients to the cells [Fomina 2006; Gheorghiade 2006]. Angiogenesis and arteriogenesis involve some soluble factor (mediator) such as nitric oxide, VEGF, basic fibroblast growth factor (BFGF), human growth factor (HGF), or angiopoietin. These

Table 2. VEGF Increments in the 2 Groups

\begin{tabular}{|c|c|c|c|}
\hline \multicolumn{4}{|c|}{$\operatorname{VEGF}(\mathrm{pg} / \mathrm{mL})$} \\
\hline Postoperative & $49.46(11.98-90.92)$ & $19.88 \pm 33.78$ & .31 \\
\hline Change in VEGF & $14.19 \pm 98.58 *$ & $-20.58 \pm 31.50 \dagger$ & .01 \\
\hline
\end{tabular}

NS indicates not significant.

$* \mathrm{P}=.203$ versus baseline.

$\dagger P=.063$ versus baseline. 
mediators cause migration of endothelial cells and vascular smooth muscle cells; proliferation, enlargement, and maturation of blood vessels; and synthesis of the extracellular matrix [Gnecchi 2008].

In humans, VEGF has several types including VEGF-A, $-\mathrm{B},-\mathrm{C},-\mathrm{D}$, and placental growth factor (PlGF). Every VEGF receptor (VEGFR) can bind to several VEGF molecules; for example, VEGFR-1 can bind to VEGF-A, VEGF-B, and PlGF; VEGFR-2 can bind to VEGF-A, -C, and -D; and VEGFR-3 can bind to VEGF-C and -D [Goldstein 1992]. VEGF-A works directly and indirectly through angiogenesis and mobilization of stem cells in infarcted hearts through stromal cell-derived factor $1 \alpha(\mathrm{SDF}-1 \alpha)$. VEGF-B increases the number of stem cell-resident c-kit receptors while inducing the expression of SDF- $1 \alpha$ and HGF, triggering stem cell mobilization and inducing angiogenesis and vasculogenesis. VEGF-C and -D induce lymphangiogenesis [HaxhibeqiriKarabdic 2014].

According to the research of Nasseri et al [2014] and Lazar et al [2018], VEGF has an important role in the process of myocardial regeneration. First, exosomes are released from ischemic cell, and the production of VEGF is induced by resident cells and stem cells, which then, through the paracrine effect, lead the process of neovascularization, cardiomyogenesis, and extracellular matrix improvement [Dimmeler 2005; Fomina 2006]. Neovascularization improves the perfusion of myocardium through vasculogenesis, angiogenesis, and arteriogenesis. Adult stem cells can also induce cardiomyogenesis through different mechanisms including trans-differentiation and merging (cell fusion), although the paracrine effect produces new cardiomyocytes by the activation of cardiac stem cells and the proliferation of resident cardiomyocytes. The paracrine effect also improves extracellular matrix through inhibition of cell apoptosis and fibrosis [Gnecchi 2008].

VEGF is produced by stem cells and resident cells that are previously mediated by the release of exosomes from stem cells. Because of the addition and implantation of stem cells, which also produce exosomes that activate VEGF, VEGF levels in the treatment group are higher than in the control group. The significantly higher levels of VEGF in the treatment group lead to myocardial regeneration, resulting in improvement of ejection fraction, scar size, and WMSI by cardiac MRI examination [Haxhibeqiri-Karabdic 2014]. Although the improvement of myocardial perfusion and ventricular dimensions was not significant in the treatment group, VEGF levels are expected to continue the improvement of perfusion, cardiomyogenesis, and extracellular matrix, leading to improvement of cardiac function. These factors increase the quality of life of the patients [Nesteruk 2016].

\section{Conclusions}

When the cell is in ischemic conditions, it produces exosomes, which activate several dissolved factors through paracrine mechanisms, such as nitric oxide, VEGF, BFGF, HGF, and angiopoietin. These factors play a role in the mechanism of myocardial regeneration to repair infarcted tissue through angiogenesis, cardiomyogenesis, apoptosis inhibition, and

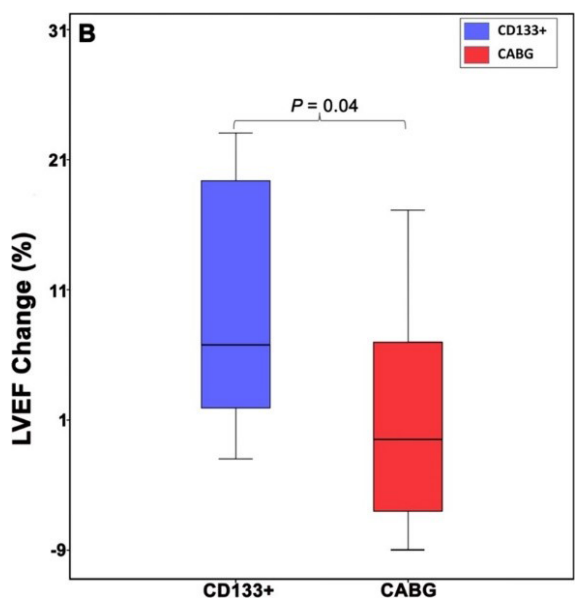

Figure 1. Boxplot (median and minimum/maximum) comparing LVEF changes of treatment $\left(\mathrm{CD} 133^{+}\right)$and control (CABG only) groups. LVEF improvement in the treatment group was significantly higher than in the control group $(\mathrm{P}=.04)$.

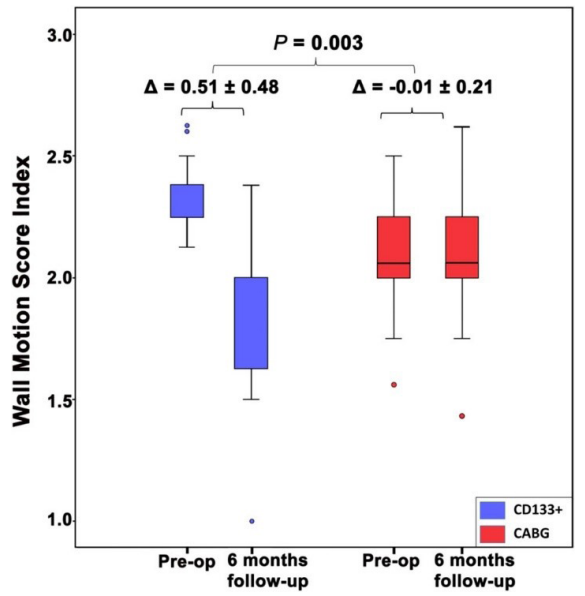

Figure 2. Boxplot (median and minimum/maximum) comparing WMSI changes of treatment (CD133+) and control (CABG only) groups. The decrease of the WMSI score $(\Delta)$ in the treatment group was significantly lower than in the control group $(P=.01) . \Delta$ is presented as mean \pm SD

extracellular matrix formation. In this study, we investigated VEGF levels with ELISA. CD133 + stem cell implantation improves myocardial function as shown by cardiac MRI and increased VEGF levels in the blood. The increase in VEGF levels is expected to continue the restoration process of myocardial function when the perfusion improvement of myocardium is still not optimal.

\section{ACKNOWLEDGMENTS}

The authors would like to thank Bagus Ronidipta Pradana, Lisca Namretta, Andhika Citra Buana, Marliando Catur Pangestu and all of the research assistant in Harapan Kita National Cardiovascular Center 


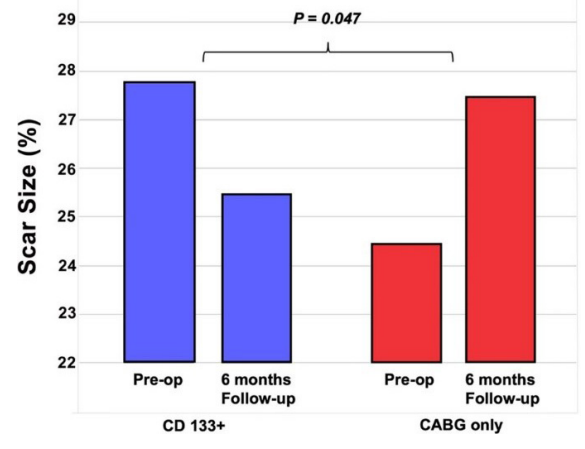

Figure 3. Boxplot (median and minimum/maximum) comparing scar size proportion improvement $(\Delta)$ between the treatment (CD133+) and control (CABG only) groups. Scar size proportion decreased in the treatment group but increased in the control group. $\Delta$ is presented as mean $\pm \mathrm{SD}$.

\section{REFERENCES}

Ahmadi H, Baharvand H, Ashtiani SK, et al. Safety analysis and improved cardiac function following local autologous transplantation of CD133(+) enriched bone marrow cells after myocardial infarction. Curr Neurovasc Res 2007;4:153-160.

Dawn B, Abdel-Latif A, Sanganalmath SK, Flaherty MP, Zuba-Surma EK. Cardiac repair with adult bone marrow-derived cells: The clinical evidence. Antioxid Redox Signal 2009;11:1865-1882.

Dimmeler S, Zeiher AM, Schneider MD. Unchain my heart: The scientific foundations of cardiac repair. J Clin Invest 2005;115:572-583.

Fomina IG, Georgadze ZO, Galanina NA, Gaidamakina NE, Kiniasheva NB. The role of interventricular septum in kinetics of left and right ventricular contraction in patients with ischemic heart disease and chronic cardiac failure. Ter Arkh 2006;78:19-24.

Gheorghiade M, Sopko G, De Luca L, et al. Navigating the crossroads of coronary artery disease and heart failure. Circulation 2006;114:1202-1213.

Gnecchi M, Zhang Z, Ni A, Dzau VJ. Paracrine mechanisms in adult stem cell signaling and therapy. Circ Res 2008;103:1204-1219.

Goldstein JA, Tweddell JS, Barzilai B, Yagi Y, Jaffe AS, Cox JL. Importance of left ventricular function and systolic ventricular interaction to right ventricular performance during acute right heart ischemia. J Am Coll Cardiol 1992;19:704-711.

Haxhibeqiri-Karabdic I, Hasanovic A, Kabil E, Straus S. Improvement of ejection fraction after coronary artery bypass grafting surgery in patients with impaired left ventricular function. Med Arch 2014;68:332-334.

Lazar E, Benedek T, Korodi S, Rat N, Lo J, Benedek I. Stem cell-derived exosomes: An emerging tool for myocardial regeneration. World J Stem Cells 2018;10:106-115.

Li G, Luo B, Lv Y, et al. Dual effects of VEGF-B on activating cardiomyocytes and cardiac stem cells to protect the heart against short- and long-term ischemia-reperfusion injury. J Transl Med 2016;14:1-14.

Nasseri BA, Ebell W, Dandel M, et al. Autologous CD133+ bone marrow cells and bypass grafting for regeneration of ischaemic myocardium: The Cardio133 trial. Eur Heart J 2014;35:1263-1274.

Nesteruk J, Steinhoff G. Long-term results of intramyocardial CD133+ bone marrow stem cell therapy for myocardial ischemia: Experience with stem cell register. Cell Ther Transplant 2016;5:20-25.

Shibuya M. Vascular endothelial growth factor (VEGF) and its receptor (VEGFR) signaling in angiogenesis: A crucial target for anti- and proangiogenic therapies. Genes Cancer 2011;2:1097-1105.

Steinhoff G, Nesteruk J, Wolfien M, et al. Stem cells and heart disease: Brake or accelerator? Adv Drug Deliv Rev 2017;120:2-24.

Strauer BE, Brehm M, Zeus T, et al. Repair of infarcted myocardium by autologous intracoronary mononuclear bone marrow cell transplantation in humans. Circulation 2002;106:1913-1918.

Urbich C, Dimmeler S. Endothelial progenitor cells: Characterization and role in vascular biology. Circ Res 2004;95:343-353. 